\title{
OPONIBILIDAD DE LAS FRANQUICIAS EN LOS CONTRATOS DE SEGUROS: ENTRE LA RAZONABILIDAD Y LA JUSTICIA
}

VERONICA MARIA LAURA GLIBOTA LANDRIEL

FACULTAD DE CIENCIAS ECONOMICAS - UNNE 


\title{
RESUMEN
}

\begin{abstract}
a irrupción al mundo jurídico del instituto de la franquicia en los contratos de seguro ha venido a producir un quiebre en la forma de considerar e interpretar los alcances subjetivos de las relaciones negociales: desde entender que los acuerdos sólo deben generar consecuencias para las partes a la idea de que frente al caso de seguros de responsabilidad civil, los efectos de la misma deben considerarse respecto del tercero damnificado, resultando inoponible la limitación de riesgos a la víctima. En este trabajo pretendemos aunar estas posturas antitéticas a través del principio de razonabilidad de la cuantía de la franquicia, el que permitiría una valoración más cercana a la justicia en las soluciones propugnadas por los jueces.
\end{abstract}

Palabras clave: Contrato de Seguro - Responsabilidad civil - Limitación de riesgo - Franquicia de seguros - Cláusula abusiva.

\begin{abstract}
The appearance in the juridical area of the exemption in the contracts of insurance, has come to modify the way of interpreting the subjective scopes of the business relationship: from understanding that the agreements only generate consequences for the parts, to the idea of that of insurances of civil responsibility, the effects must consider to be a respect of the damaged third party, and the limitation of the risks can't be opposed to the victim. In this work we try to bring over these positions objected across the rasonability principle to amount of the exemption, which would allow a valuation nearer to the justice in the solutions of the judges.
\end{abstract}

Keywords: Contract of insurance - Civil responsibility - Limitation of risk - Exemption of insurance - Abusive clause.

\section{INTRODUCCIÓN}

"El ser humano asume la inseguridad, pero busca seguridad y entre los caminos para lograrla está la responsabilidad. Como tiene necesidad de seguridad, incluso respecto de la responsabilidad, ha ideado la respuesta compleja del aseguramiento individual y social. Diferenciado, pero integrado en el complejo del aseguramiento, el seguro es un contrato oneroso encaminado a superar la inseguridad produciendo seguridad" (CIURO CALDANI, 2011).

El último párrafo de la cita precedente traduce innegablemente el fin de la génesis del fenómeno del aseguramiento en la era moderna y demuestra el carácter imprescindible que tiene este contrato en la realidad social de nuestros días. Vivimos en una era de constantes y fabulosas innovaciones científicas, tecnológicas y morales. Sólo por dar un ejemplo, la incursión en la experimentación en el campo de la genética humana. Por ello se ha dicho que ésta debe ser enten- 
dida como la verdadera "era de los riesgos". Frente a ello, es poco discutible el papel preponderante que tienen los contratos de seguro y el estado de expansión que los mismos han alcanzado respecto de situaciones y actividades que forman parte del accionar humano en la actualidad.

$\mathrm{Su}$ esencia estriba en la distribución de los efectos económicos desfavorables de unos riesgos, entre los patrimonios individuales que están expuestos a ellos.

Se ha dicho que una de las principales funciones del seguro está constituida por la posibilidad de "previsionar" toda clase de siniestros (esto es: eventos dañosos, futuros, inciertos). Y son esos eventos (o mejor la posibilidad de que ocurran) en su interacción con el interés, los que dan sustento al sistema asegurativo (Conf. MOLINA SANDOVAL, 2006).

Mediante el uso de este instituto jurídico se procura vencer aquellos límites que se oponen a lo asegurado, sirviendo como vehículo de desarrollo de las actividades que dan impulso a la vida y la economía de todo Estado.

En el presente trabajo, pretendemos ahondar sobre una de las facetas que presenta el instituto altamente tecnificado del seguro: es el fenómeno de la "franquicia". Esto es, la ya difundida práctica de incorporar en el contrato de seguro una cláusula por la que se limita o restringe la responsabilidad de la empresa aseguradora en función de la cuantía de la reparación o indemnización a pagar, con diferentes modalidades y peculiaridades.

En nuestro país, la polémica acerca de la oponibilidad o inoponibilidad de las franquicias de seguros de responsabilidad civil a las víctimas de daños, viene trascendiendo las fronteras de la doctrina y se ha traducido en una verdadera contienda de fundamentos dogmáticos y filosóficos en el ámbito de las decisiones propugnadas por los Tribunales de la más alta jerarquía judicial.

Frente a los sucesivos fallos pronunciados a razón de los plenarios de las Cámaras Nacionales Civiles de Apelación, y las revisiones por vía extraordinaria de los mismos realizadas por el Máximo Tribunal de Justicia del país, es dable intentar -a través de una sinopsis- un análisis del estado de situación que presenta la jurisprudencia argentina respecto del tópico en cuestión, adelantando como conclusión la necesidad de interpretar las cláusulas de incorporación de franquicias en los seguros de responsabilidad civil, como un instituto perfectamente válido y eficaz -además de necesario-, y oponible a los damnificados en función de la razonabilidad de la cuantía y de un verdadero equilibrio económico de las prestaciones derivadas del acuerdo negocial.

Desde otro punto de vista -pero obedeciendo al fin de demostrar la importancia y actualidad jurídica del tema-, y situándonos en la perspectiva que sustenta nuevas funciones para la responsabilidad por daños - que se unirían a la tradicional de la reparación de los perjuicios-, y en particular del fin tutelar preventivo al que debe orientarse la interpretación y aplicación de las normas de responsabilidad civil.

La evolución de las finalidades del sistema de responsabilidad civil se ha basado en la mudanza de una serie de paradigmas, al decir de Lorenzetti: "de responsabilidad como deuda a la responsabilidad como crédito a la indemnización”, del "daño a la propiedad" al “daño a la persona”, del daño individual al daño colectivo, de la reparación a la prevención” (LORENZETTI, 2010). 
Desde la perspectiva de la teoría del Análisis Económico del Derecho (AED), no podemos dejar de mencionar que la franquicia en los seguros puede ser considerada una forma económicamente eficaz para incentivar las conductas diligentes del asegurado tendientes a evitar la causación de daños, por los que debe responder de manera directa.

Para hacer más clara aún la idea, el AED postula que un individuo racional (homo economicus) no se comportará del mismo modo si se enfrenta a la amenaza de ser condenado a pagar una indemnización que si no la enfrenta (CALABRESI, 1970). La franquicia, en cierta forma, vendría a actualizar o hacer resurgir la concepción de la asunción de los riesgos por parte del asegurado estimulando, en consecuencia, la conducta diligente del mismo en la evitación del siniestro.

\section{NOCIONES CONCEPTUALES ACERCA DE LA FRANQUICIA EN LOS CONTRATOS DE SEGURO}

De este estado de situación se deriva que, son los usos comerciales los que van delineando las modalidades que este instituto adquiere, siendo las más usuales, las franquicias condicionales, relativas o simples y las incondicionales, múltiples, absolutas o deducibles.

Se puede definir a la franquicia como la cláusula incorporada al contrato de seguro por la que se pacta que, en caso de siniestro, la compañía aseguradora asume la obligación de pagar la totalidad de la indemnización o bien el excedente, siempre que la suma de los daños supere el monto establecido en dicha cláusula, hasta cubrir el importe asegurado.

Hasta aquí, la franquicia está definida desde la fijación de topes o quantum específicos, que habilitan el derecho del asegurado a ser cubierto por los daños a su interés asegurado, sea de manera total o parcial, asumiendo en este último caso, la responsabilidad de manera directa por los daños que no superen dicho tope.

Sin embargo, el concepto también puede ser entendido desde una limitación temporal de cobertura, que permite incluir las llamadas cláusulas claims made.

Sin perjuicio de ello, tomamos el concepto primeramente expuesto como universo de este análisis.

El principio en materia de seguros que sustentaría el instituto de la franquicia es que el asegurador debe indemnizar al asegurado el daño que éste ha sufrido -la afectación a su interés asegurable-, a consecuencia de un siniestro cubierto por la póliza, dentro de los alcances, límites y condiciones establecidos en la misma.

A este respecto, se ha opinado que, justamente, "uno de los límites es el que se presenta con la incorporación en la respectiva póliza de una franquicia; es decir, de una parte del daño que, en caso de ocurrir el evento siniestral amparado por el contrato de seguro, deberá ser tomado en cuenta para determinar el derecho del asegurado a ser indemnizado -franquicias simples o condicionales- o para fijar el monto de la indemnización -franquicias absolutas, incondicionales o deducibles-" (LOPEZ SAAVEDRA, 2007; p.p. 311-312).

Desde esta perspectiva, podemos definir a las franquicias condicionales, relativas o sim- 
ples, como aquéllas en las que el asegurador se obliga a indemnizar al asegurado, siempre y cuando el daño exceda la suma o el porcentaje establecido en la póliza como franquicia. Cuando esto ocurra, el asegurador indemnizará el total del mismo, sin deducciones. Otros autores sostienen que se trata de franquicias típicas o estructurales (MEILIJ, 2012).

En cambio, en las franquicias incondicionales, múltiples, absolutas o deducibles, el asegurador también se obliga a indemnizar al asegurado como consecuencia del siniestro cuando el daño supera la franquicia establecida en la póliza; pero la indemnización a pagar alcanzará solamente el excedente de la franquicia. El deducible puede ser fijo -una suma determinada- o en un porcentaje sobre el total.

Algunos autores distinguen a la franquicia de lo que denominan descubierto obligatorio $^{1}$. Como se observa, esta figura presenta una similitud con la franquicia en su finalidad y consecuencias, aunque la franquicia puede llevar aparejado o no un descubierto.

Tanto la franquicia como el descubierto obligatorio cumplen una función análoga, aunque presentan diferencias en cuanto al pago de la prima y a los alcances de la indemnización a cargo del asegurador, en los casos de una franquicia deducible. (LÓPEZ SAAVEDRA, 2007).

Asimismo, la causa por la que una parte del daño es soportado por el asegurado es distinta en un caso y en el otro. En el descubierto la causa es un infraseguro que deriva de la decisión del asegurado; en cambio, en la franquicia deducible, la disminución de la indemnización es consecuencia de una estipulación específica de la póliza, en la que puede no existir un infraseguro.

La reducción de las primas en los seguros con franquicia obedece a una inocultable finalidad técnica, que es eliminar la garantía frente a siniestros de poca monta, que podrían resultar eficientes para la aseguradora en orden a que los gastos de liquidación y administración de dichas primas excederían en algunos casos el propio daño.

Resultan de una claridad meridiana las expresiones de Gustavo Meilij cuando afirma "ambas circunstancias (franquicia y descubierto obligatorio) tienen por objeto desentenderse de los pequeños siniestros, que originan gastos administrativos inadecuados y mejorar en la práctica el cuidado del riesgo, poniendo a cargo del asegurador parte de los daños ocasionados por el siniestro" (MEILIJ, 2012; p.207).

De allí que, tratándose de una franquicia, nada obsta a que se ampare el tramo descubierto con otro seguro, no así en el descubierto obligatorio, lo que podría generar reticencia o agravación del riesgo.

\footnotetext{
${ }^{1}$ En opinión de López Saavedra -que compartimos-, la franquicia y el descubierto obligatorio, involucran conceptos diferentes, pero coinciden en sus efectos y consecuencias. El descubierto se vincula al concepto de infraseguro, es decir, al caso en que la suma asegurada es inferior al valor total del interés asegurable, situación que origina la aplicación de la llamada regla proporcional; en cambio en la franquicia puede no existir infraseguro, aunque el asegurado termina soportando una parte del daño sufrido en su interés asegurable.
} 


\section{REGULACION LEGAL DE LA FRANQUICIA EN LA ARGENTINA}

La ley 17418 no define ni regula las modalidades de limitación de la prestación a cargo del asegurador. De allí que la fuente obligatoria en esta materia resulta, en la generalidad de los casos, del consenso de las partes, que materializa el contrato de seguro.

En el caso de los seguros de responsabilidad civil obligatorios, también existen lagunas legales, ya que la regulación que impone la franquicia en los contratos de seguro de transporte automotor de pasajeros, deviene de la Resolución No 25429, de la Superintendencia de Seguros de la Nación.

\section{LA FRANQUICIA: CLÁUSULA DE LIMITACIÓN DE RESPONSABILIDAD O DE LIMITACIÓN DEL RIESGO ASEGURADO}

En este punto, cabe distinguir tres tipos de cláusulas, que han sido enunciadas y analizadas en profundidad por la doctrina española, y que puedan estar presentes en los contratos de seguros. Dichas cláusulas presentan diferenciados efectos o consecuencias previstos en el ordenamiento jurídico español, los que van desde la inexistencia como tal (por ser consideradas cláusulas abusivas), a la necesidad de controles de contenido y por último la plena validez. En cada caso, pretendemos analizar su admisión o no como tipo específico de cláusula contractual y su previsión en nuestro ordenamiento jurídico o la interpretación doctrinara al respecto.

A los fines de poder entender con mayor claridad diremos que entre los casos más frecuentes de cláusulas limitativas en los contratos de seguros, sin la previa distinción conceptual, encontramos a: la exclusión de responsabilidad de las aseguradoras por conducción de vehículos sin autorización, o bajo los efectos del alcohol, o drogas (comúnmente denominadas de exclusión de cobertura); las cláusulas de exclusión de determinadas personas del ámbito subjetivo de la cobertura ${ }^{2}$; exclusión de responsabilidad cuando el siniestro se deba a impru-

\footnotetext{
${ }^{2}$ Al respecto, un fallo de CNCiv. Sala K, 2006/04/06 "Artuso Juan y otros c. Anechine, Guillermo y otros", se pronunció por considerar la cláusula de ampliación de "no seguro", como abusiva: "Cabe rechazar la excepción de falta de legitimación pasiva opuesta por la aseguradora, citada en garantía, fundada en que el conductor del vehículo embistente se encontraba en estado de ebriedad al momento del accidente, toda vez que la cláusula por la que se amplía el "no seguro" resulta abusiva, pues su aplicación suprime la obligación de la compañía de seguros, en contra de los dispuesto por el art. 158 Ley $17.418 . . .$. De resultar válida dicha normativa orientada a la exclusión de la cobertura, ello conspiraría contra normas de orden público contenidas tanto en la Ley 24.240 , como en el Código de Tránsito de la Prov. de Buenos Aires..." en Revista de Responsabilidad Civil y Seguros. Año VIII, N VIII. 2006. Ed. La Ley. Agosto de 2006. Pág. 78-84.

${ }^{3}$ Al respecto, la CNCom. Sala B, 2004/12/21, "Magnante de Montes, Dinah c/ Galicia Vida Cía. de Seguros": "El factor liberador de responsabilidad dispuesto por los arts. 70 y 114 de la ley 17.418, mediante el cual están a cargo de la compañía aseguradora los siniestros ocurridos mediando culpa grave del asegurado sólo se producirá cuando la provocación sea imputable en grado de culpa grave , la que se evidencia cuando la conducta desborda el novel medio de la negligencia o la imprudencia es rayana con él, y por ende, existirá cuando el asegurado omita la diligencia elemental de las personas menos previsoras y más especialmente cuando incurra en ella por estar asegurado", en Revista de Responsabilidad Civil y Seguros. Año VII, N V 2005. Ed. La Ley. Mayo de 2005. Pág. 108-112.
} 
dencia del asegurado3; las llamadas "claims made"4 en el ámbito de la responsabilidad civil particularmente presentes en el aseguramiento de la actividad de los profesionales de la salud; las limitaciones al objeto del seguro o riesgo asegurado ${ }^{5}$; entre otras.

Dentro de la clasificación aludida al inicio de este punto, se hallan las denominadas "cláusulas abusivas”, son aquéllas que contrarían el equilibrio contractual, tornando desproporcionados los derechos de una parte (la aseguradora) frente a la otra (el asegurado). En relación a esta primera calificación, de hallarse incluidas en el contrato de seguro, deben reputarse nulas y tenerse por no incorporadas al mismo.

Son aquellas que, sin contravenir las disposiciones imperativas de la Ley de Seguros, y sin ser especialmente negociadas entre las partes, pueden reputarse inicuas, desproporcionadas o injustas, o simplemente "abusivas". Estas, sucumbirían al control de contenido, previsto en el art. 37, de la Ley 24240, si estuvieran incorporadas a contratos de consumo.

Las denominadas "cláusulas limitativas de los derechos del asegurado", en cambio, son aquellas que, sin llegar a ser desproporcionadas o inicuas, empeoran la posición contractual del consumidor o cliente, ya sea cercenando los derechos que la ley o el contrato le reconocen, o imponiéndole nuevas obligaciones. En el derecho español, sólo se admiten si han sido conocidas y aceptadas especialmente por el asegurado, en cuyo caso pasan a formar parte del contrato, pero aún pueden quedar sometidas al control de contenido, y en función de éste ser declaradas nulas por abusivas. La diferencia con las cláusulas lesivas radica en que éstas son, prima facie, inválidas e ineficaces en todo caso, en tanto, las primeras podrían considerarse válidas en el caso en que mediara aceptación expresa, salvando el posterior control de contenido.

"Las cláusulas limitativas que, aún habiendo pasado a formar parte del contrato, no superen este control (de contenido), deberán considerarse cláusulas lesivas y por tanto, declararse nulas y tenerse por no puestas, igual que puede suceder con cualquier cláusula contenida en condiciones generales o particulares aún cuando no sea limitativa”. (PAGADOR LOPEZ, 1999; p.p. 378)

En lo que se refiere a este punto, el art. 158, último párrafo de la ley de seguros argentina prescribe a este respecto: "Cuando las disposiciones de las pólizas se aparten de las normas legales derogables, no podrán formar parte de las condiciones generales”.

Por lo que las modificaciones deberán formar parte de condiciones especiales, sometidas

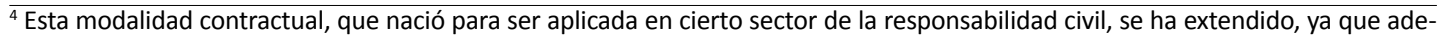
más de encontrarse prevista en todo supuesto de responsabilidad profesional -abogados, médicos, etc.-, también se utiliza en materia de contaminación ambiental. Por medio de la incorporación de este tipo de cláusula, se establece que la cobertura que se otorga ampara la responsabilidad civil del asegurado, siempre y cuando el "reclamo" se formule dentro del período de vigencia material del contrato, sus renovaciones o dentro del plazo del período de extensión de denuncia del siniestro. Fuente: La cláusula "Claims Made", por siempre ilícita, http://es.shvoong.com/law-and-politics/contract-law/480794-la-cl\%C3\%A1usula-claims-por-siempre/.

${ }^{5}$ La jurisprudencia ha establecido: "El riesgo debe ser debidamente individualizado o precisado, y en caso de dudas acerca de su extensión se debe estar por la obligación del asegurador. Ello así porque él es el que redacta las condiciones del contrato y, por lo demás es el que está en mejores condiciones que el asegurado para fijar precisamente la extensión clara de sus obligaciones". CNCiv. Sala B, 2006/03/01 "Zalazar, Karina c. Gonzalez Maccarrone de Carrela, Ana, en Revista de Responsabilidad Civil y Seguros. Año VIII, N VII. 2006. Ed. La Ley. Julio de 2006. Pág. 102-108.
} 
a la aceptación y la negociación particular.

Sin perjuicio de ello, no podemos obviar que la Ley 24240, prescribe en su art. 37, inc. b), como supuesto que amerita la calificación de abusiva, a las cláusulas en los contratos de adhesión con consumidores "que importen renuncia o restricción de los derechos del consumidor o amplíen los derechos de la otra parte”; de donde, las limitaciones a los derechos del asegurado, aun cuando hayan traspasado el control de inclusión, a través de la firma específica del adherente, o como cláusula particular del contrato, no podrán soslayar el control de contenido previsto a partir de esta norma, reputándose como no escritas. Pareciera que en nuestro ordenamiento jurídico, no cuadra la distinción de grados, y ambas deben a la postre recibir la misma calificación de "abusivas".

De acuerdo a la consideración de la jurisprudencia, se ha entendido formando parte de esta categoría a las cláusulas claims made, por contrariar las disposiciones de la Ley 24240 en tanto cláusula que amplía injustificadamente los derechos del asegurador, limitando los del asegurado ${ }^{6}$.

Por último, las "cláusulas de delimitación del riesgo asegurado", no son, en rigor de verdad, limitaciones a los derechos de los asegurados, sino que vienen a determinar el objeto del contrato, de conformidad con criterios de normalidad o tipicidad; esto es, de acuerdo a lo que habitualmente es de uso en el comercio de seguros incluir como riesgo indemnizable en cada tipo de contrato. Recordemos que en el contrato de seguro, el asegurador no puede asumir el riesgo de una manera abstracta, sino que éste deber ser debidamente individualizado, ya que no todos los riesgos son asegurables, es por ello que deben limitarse e individualizarse dentro de la relación contractual.

Estas cláusulas regulan elementos esenciales del contrato como es el "riesgo asegurable", en función del cual se calcula la prima. En relación a ellas, se afirma, desde este enfoque, que la distinción entre ambos tipos de cláusulas, se sustenta en criterios lógicos y cronológicos, de tal modo que las cláusulas delimitadoras del riesgo se estiman pertenecientes a una primera fase de atribución contractual de derechos al asegurado, o, lo que es lo mismo, de asunción de obligaciones correlativas por el asegurador; mientras que las cláusulas limitativas de los derechos del asegurado se sitúan en un segundo momento de limitación de los derechos, previamente atribuidos por ley o por el contrato.

Ahora bien, en aquellos casos en que las cláusulas excluyan o limiten los riesgos propios o típicos de cada contrato de seguro, pueden quedar sometidas al control de inclusión, requiriendo entonces una aceptación especial o expresa de las mismas. Pero una vez realizado, pasan a formar el contenido del mismo, y a diferencia de las demás cláusulas de limitación

\footnotetext{
6 “Ello, desnaturaliza la función económico-jurídica del contrato. La aprobación de los planes de seguros por parte de la Superintendencia de Seguros de la Nación no sería suficiente para admitir la validez de este tipo de cláusulas". CNCiv., sala C in re "Barral de Keller Sarmiento, Graciela c/ Guevara, Juan Antonio y otros s/ daños y perjuicios", 02/05/2006. Nos resulta importante comentar que del fallo se desprende que la Cámara parece dejar abierta la posibilidad de convalidar las cláusulas de este tipo, si la aseguradora acredita haber ofrecido alternativas de cobertura suficientes, con lo cual, nos parece que comienza a abrirse paso la postura de considerar la eficacia de este tipo de cláusulas cuando sea admitida de entre una serie de propuestas a la medida de cada asegurado.
} 
de derechos del asegurado, no pueden ser sometidas a control de contenido. Aún así, podrían generar la responsabilidad del asegurador por su carácter de cláusula sorprendente.

Desde este punto de vista, las cláusulas delimitadoras del riesgo no pueden reputarse cláusulas limitativas de los derechos de los asegurados, en el sentido que recoge la ley de Defensa del Consumidor argentina (como cláusula abusiva), máxime si se considera que las referidas limitaciones han sido tenidas en cuenta en el cálculo de la prima abonada por el tomador. Por ende, debe entenderse que no revisten el carácter de cláusulas abusivas, ni reciben el tratamiento de condiciones inexistentes (se tienen por no escritas, según reza la norma tuitiva argentina).

Para una relevante corriente doctrinal, sin embargo, debe prescindirse de un enfoque exclusivamente conceptualista a la hora de abordar el problema debatido y, en su lugar, atender a los efectos producidos por las cláusulas, particularmente desde la perspectiva de la posición de los asegurados.

En este sentido, se señala que "no obstante admitirse que una cláusula insertada en una póliza para delimitar el riesgo asegurado no es, en principio, una cláusula limitativa, no cabe desconocer que, al fin, se convierte en una de ellas, ya que una y otra producen el mismo resultado: limitan los derechos de los asegurados como consecuencia del establecimiento de exclusiones a la cobertura del asegurador". (PEREZ-SERRABONA GONZALEZ, 1993; p.p. 272-274).

En esta línea de pensamiento, se ha postulado, frente a una concepción estricta o literal, un entendimiento amplio de las cláusulas limitativas, en cuyo seno podrían encontrar cabida las cláusulas de delimitación del riesgo. Y es que, como ocurre en general con todas las condiciones de la póliza, las partes pueden acordar libremente los límites de la cobertura. En tal sentido, y dentro de los límites previstos en la ley, el asegurador puede excluir del seguro determinados daños o acontecimientos (TAMAYO JARAMILLO, 1999; p. 95). En última instancia, todo resulta en el control, derivado de las consecuencias de la aplicación de tales cláusulas.

La delimitación del riesgo asegurado, implica para el asegurador expresar el límite de la disponibilidad de cobertura, puesto que el precio que se cobra por ella depende de la indemnización a pagar en caso de que acontezca el siniestro en la forma prevista en la póliza.

Es bien sabido que aquellas condiciones que han sido negociadas individualmente no podrán ser nunca consideradas lesivas, en cuanto abusivas, puesto que la negociación individual excluye la idea del abuso (salvo caso de lesión) y, por tanto, la razón de ser del control instaurado legalmente. Podrán ser, eso sí, nulas o ineficaces, por vulnerar una norma de carácter imperativo, pero no lesivas.

Desde otra perspectiva, "es obvio que nunca podrán considerarse lesivas las condiciones que regulen aspectos esenciales del contrato, es decir, los presupuestos básicos sobre los cuales recae el consentimiento (hautdedingungen), entre las cuales hay que incluir, necesariamente, las cláusulas que delimitan el riesgo que va a ser objeto de la cobertura" (FONT RIBAS, 1999; p.14).

Es claro entonces que las limitaciones al riesgo asegurado forman parte de la necesaria delimitación del objeto contractual, y de allí que resultan completamente válidas y eficaces entre las partes del acuerdo, si no ha mediado mala fe o violación al deber de información por 
parte del predisponente del contenido contractual.

Ahora bien, podemos afirmar que la franquicia constituye una forma de limitación al riesgo asegurado y desde este punto de vista, la misma no podría ser considerada una cláusula abusiva per se.

Meilij, al distinguir la franquicia del descubierto obligatorio, sostiene que el elemento distintivo finca en el hecho que la franquicia "integra" el riesgo amparado, delimitando su estructura de procedencia (MEILIJ, 2012; p. 207).

La jurisprudencia argentina así lo viene sosteniendo en distintos fallos: "En el contrato de seguro existe un acuerdo de voluntades entre los estipulantes que implica, por lo menos coincidencia de ambos sobre la determinación del riesgo cuya cobertura se intenta.... El conjunto de tales delimitaciones perfila el denominado riesgo asegurable. Desbordadas las mismas no existe seguro (arts. 499, 910, 1144 y ss., 1197,1198 C. Civ; 1, 11, 12, 60, 109 y concs., Ley 17418)... Una de ellas es la franquicia, o "descubierto obligatorio", limitación que se verifica cuando el asegurado está obligado a conservar a su costa una cierta parte del daño, cualquiera sea la importancia del mismo...”

En idéntico sentido: "Existiendo la cláusula de franquicia pactada contractualmente entre la compañía y el asegurado por la cual pone un límite al riesgo cubierto de acuerdo a la normativa legal prevista, ello conduce a concluir que el descubierto obligatorio es oponible al tercero damnificado y que la sentencia no podrá ser ejecutada contra la aseguradora sino en los límites de la contratación”.

\section{CONSIDERACIONES ACERCA DEL SEGURO Y LA FRANQUICIA DESDE EL ANÁLISIS ECONÓMICO DEL DERECHO}

Partimos de la base de que la corriente más tradicional dentro de la teoría del AED no considera la posibilidad de contratar seguros en los modelos analíticos más simples. Es a partir del trabajo de Calabresi, relativo a los costes de los accidentes, y la posibilidad de dispersión de los riesgos, que se comienza a incluir la consideración de la asignación y distribución de los mismos, lo que implica incorporar en el modelo económico de la responsabilidad por daños, la posibilidad de que los dañadores, o las víctimas, contraten un seguro.

Desde este enfoque, el seguro voluntario permite una asignación y distribución de riesgos eficiente. Esto significa que se trata de un instrumento que permite que aquellas partes que

\footnotetext{
${ }_{7}$ CCCom. de San Isidro, sala III, 5/5/2009, "Silva c/ La Independencia”, “Di Gaudio c/ La Independencia” y "Peruzzo c/ La Independencia", disponible en: www.casi.com.ar, ID: 4654, consultado el 20/10/2012.

${ }^{8}$ CCCom. de Lomas de Zamora, sala III, 18/02/2010, "Juanolo Hernán c/ Servilla José s/ daños y perjuicios"; Idem: SCBA, C. 105.026 S, 21/09/2011, “Ludueña, Miguel c/ Expresa Caraza SA y otros s/Daños y perjuicios”, JUBA; Idem: CCCom. de Quilmes, sala I, 14/10/2008, "Coronel, Cristina Graciela c/ Expreso Quilmes SA y otros s/ Daños y perjuicios, JUBA Sum. B2904227, consultados en Revista de Derecho de Daños 2012- 1, Sección Jurisprudencia Nacional. Ed. Rubinzal- Culzoni. P.p. $422 / 425$.
} 
sean adversas al riesgo no deban soportarlo y, puedan transferirlo a quienes sean neutrales frente al riesgo.

En este contexto, que un individuo sea adverso al riesgo implica que prefiera un resultado cierto, a uno incierto. De allí que estará dispuesto a pagar para evitar la incertidumbre del resultado (sea éste sufrir un daño, o pagar una indemnización en el caso de los seguros de responsabilidad civil). Para este individuo, el costo de enfrentar un resultado incierto será mayor, que afrontar un costo cierto (el del seguro), para eliminar la incertidumbre.

Los individuos neutrales al riesgo, sin embargo, tienen una actitud de indiferencia entre un resultado cierto o incierto. Luego, resulta beneficioso (incrementa los beneficios totales), eliminar o reducir el riesgo que soportan los individuos adversos y trasladarlo a los individuos neutrales frente al mismo. He aquí el fundamento económico de la existencia del seguro.

Así, la posibilidad de contratar un seguro implica la opción para los agentes adversos al riesgo, de trasladarlos al asegurador (que se asume neutral al riesgo, es decir, que le resulta indiferente), permitiendo de esa forma aumentar los beneficios totales.

Sin embargo, esta solución presenta una desventaja, ya que desde el AED se plantea que una cobertura que elimine completamente el riesgo, podría tener un efecto secundario indeseable, que se conoce como "moral hazard" (riesgo moral). Un individuo que se halla completamente asegurado frente a un determinado riesgo, será poco proclive de actuar con precaución, o diligentemente.

Entonces, la solución eficiente se plantea como aquélla en la que, la diferencia entre el costo de precaución asumido en caso de no haberse contratado el seguro, es mayor que el costo que se deja de asumir por haberlo hecho. Es decir, es probable que el asegurado no tenga incentivos para invertir en precaución, de la misma forma en que lo haría si no tuviese una cobertura completa por los daños que pueda causar, o que elija el nivel de actividad que desee sin evaluar en cuánto aumenta dicho nivel de actividad la probabilidad del daño.

En definitiva, el moral hazard implica un problema de información derivado del hecho que la aseguradora no puede observar la conducta del asegurado; si pudiese hacerlo, seguramente se encontraría en condiciones de estimar más adecuadamente el riesgo acorde a la conducta del cliente, y fijar una prima que lo refleje perfectamente.

La franquicia de los seguros, se constituye frente a este azar moral, en una alternativa válida para reducir sustancialmente el mismo, motivando conductas diligentes tendientes en cierta medida a la evitación de aquellas productoras de los daños contra los que se asegura, asumiendo en parte los riesgos de manera directa.

\section{OPONIBILIDAD O INOPONIBILIDAD DE LA FRANQUICIA AL TERCERO DAMNIFICADO: ¿OPINIONES INCONCILIABLES?}

Una vez afirmado que la franquicia constituye una cláusula de las entendidas como limitantes o delimitantes del objeto contractual -el riesgo asegurado como elemento esencial del contrato de seguro-, y a partir de allí, valorada como válida y plenamente eficaz entre las 
partes, debemos encauzarnos a analizar la eficacia de las mismas respecto de terceros y la búsqueda de fundamentos o soluciones para aunar los criterios antitéticos que existen en la doctrina judicial argentina.

Según la Ley 17418, el asegurador debe indemnizar el daño sufrido por el asegurado como consecuencia de un siniestro cubierto "dentro de los alcances, límites y condiciones establecidas en la póliza contratada” (art. 118).

Tal lo afirmado ut supra, uno de los límites a ese deber resarcitorio, lo constituye la inclusión contractual de una "franquicia"; es decir, de una parte del monto necesario para reparar el daño que, de ocurrir el siniestro será soportado íntegramente por el asegurado.

En resumen, la aseguradora limita su participación en la indemnización a una porción de la misma, de forma tal que, siempre que el daño supere el valor mínimo previsto, nacerá la obligación de indemnizar. En caso que el daño no supere el valor establecido como límite, la aseguradora no responde, sino que lo hace directamente el asegurado.

La jurisprudencia se halla claramente dividida sobre la admisibilidad de dichas cláusulas, pero circunscribiendo la disputa a la oponibilidad o eficacia en relación a terceros, víctimas del daño contra el que se asegura.

La Corte Suprema de Justicia de la Nación se ha expedido en relación a la especial situación que plantean los seguros de responsabilidad civil obligatorios en el ámbito del transporte terrestre y particularmente a la validez de la Resolución 25429 de la Superintendencia de Seguros de la Nación, que establece la franquicia también obligatoria favor de las aseguradoras a partir del límite de $\$ 40.000$, considerando que la misma es oponible al damnificado tercero en la relación contractual ${ }^{9}$.

Este fallo, significó el comienzo del encono jurisprudencial entre la Cámara Nacional Civil en pleno -que dos años antes había sentado precedente respecto de la inoponibilidad de la franquicia estableciendo la responsabilidad plena y solidaria entre asegurado y aseguradora frente a la víctima- y el Máximo Tribunal. A partir de allí, una pléyade de sentencias pronunciadas en distintas jurisdicciones y por jueces de diferentes jerarquías que vienen adhiriendo a una u otra postura para casos similares.

\section{EL PLENARIO “OBARRIO": PRINCIPALES FUNDAMENTOS A FAVOR Y EN CONTRA DE LA OPONIBILIDAD DE LA FRANQUICIA A LA VICTIMA}

El 13 de diciembre de 2006, la Cámara Nacional de Apelaciones en lo Civil, en pleno, dictó fallo plenario en autos "Obarrio, María Pía c/ Microomnibus Norte S.A. y otro s/ daños y perjuicios” y “Gauna, Agustín c/ La Economía Comercial S.A. de Seguros Generales y otro s/

${ }^{9}$ En “Obarrio, María Pía c/Microómnibus Norte”, 04/03/2008; La Ley 2008-B , 402. 
daños y perjuicios" estableciendo la inoponibilidad al tercero damnificado, de la franquicia en los seguros de responsabilidad civil de vehículos destinados al transporte público de pasajeros, que fuera prevista y regulada como obligatoria por Resolución $N^{0}$ 25429/97 de la S.S.N.

Dicha Resolución, dictada a los fines de paliar la situación de emergencia en que se hallaba el sector de empresas prestadoras del servicio de autotransporte automotor público de pasajeros -derivada de la gran cantidad de siniestros, actividad litigiosa y liquidación del Instituto Nacional de Reaseguros, entre otras causas-, aprobó las condiciones contractuales para el riesgo de responsabilidad civil de vehículos automotores destinados al transporte público de pasajeros y dispuso que los aseguradores que optaren por brindar dicha cobertura "deberán adherirse expresamente a esta Resolución".

En el Anexo III se estableció lo que se denomina franquicia o descubierto a cargo del asegurado, disponiendo que "el asegurado participará en cada acontecimiento cubierto que se tramite por la vía administrativa o judicial con un importe obligatorio a su cargo de $\$$ 40.ooo". Y añade que "dicho descubierto a su cargo se computará sobre el capital de la sentencia o transacción, participando el asegurado a prorrata en los intereses y costas".

Consideramos la trascendencia de esta decisión plenaria, en orden a la claridad meridiana con que se han expresado los fundamentos de la mayoría -a favor de la inoponibilidad de la franquicia a los terceros damnificados- $\mathrm{y}$, particularmente, los de la minoría -lógicamente a favor de la eficacia de la cláusula contractual frente a los terceros-, que luego rescatara en gran medida la Corte Suprema para avalar su propia doctrina al respecto. Nos permitimos entonces, para un mejor entendimiento, extractar aquellos que serán objeto de ponderación en el capítulo referido a los resultados de esta investigación, por guardar alguna vinculación con el tema en análisis.

Así, entre los fundamentos de la mayoría para el decisorio que destacamos, consideramos trascendentes, los siguientes:

1. "La necesidad de acoger el criterio solidarista para la reparación del daño "injustamente sufrido", y la consecuente protección de la parte débil con la consideración de la función social del seguro que tiende a sortear la eventual insolvencia del autor del daño, particularmente en actividades que evidencian gran operatividad en la generación de perjuicios".

2. "La franquicia admitida por la regulación de la SSN, desvirtúa la obligatoriedad del Seguro de Responsabilidad Civil prevista en la Ley 24449, ya que en el marco de la misma (por debajo de los \$40.00o), el asegurado carece de seguro".

3. "La función del contrato de seguro queda desnaturalizada, no sólo porque no se contemplan los derechos del asegurado, en procura de su indemnidad, sino que primordialmente se ven afectados los intereses de los damnificados por accidentes de tránsito, desvaneciéndose la garantía de una efectiva percepción de la indemnización por daños, constituyendo una violación implícita de la finalidad económico jurídica de tal contratación”.

4. "La cláusula de la póliza vulnera los límites impuestos por el art. 953 del Cód. Civ., es abusiva en los términos del art. 1071 del mismo Código e incluso, si se juzgan aplicables al caso las disposiciones que regulan la protección del consumidor (arg. Arts. 1, 2 y concordantes de la 
ley 24.240), porque deben tenerse por no convenidas las estipulaciones que desnaturalicen las obligaciones o limiten la responsabilidad por daños (art. 37, inc. 1, ley citada)".

La exorbitancia de la cuantía fijada por la Autoridad de Control del seguro es lo que se cuestiona y, en definitiva, lo que torna inoponible la franquicia. Así, sostienen al respecto:

5. "Lo que está en juego, en el caso que analizamos, es la irrazonabilidad del descubierto previsto en las pólizas del sector asegurado que nos ocupa”.

La minoría, en cambio, funda sus considerandos en los siguientes aspectos:

1. La oponibilidad de la franquicia tiene su fundamento en que en el caso no media solidaridad sino concurrencia de obligaciones con causas disímiles: la del trasportador derivada del incumplimiento contractual -si la víctima es la trasportada- o del acto ilícito -si es un tercero, peatón u otro automóvil-, mientras que la de la citada en garantía tiene su fundamento en el contrato convenido entre el primero y la aseguradora. "Son relaciones obligacionales distintas e independientes, enlazadas únicamente por el sistema instituido por la ley 17418 ".

2."De tal manera la pretensión de que la aseguradora se haga cargo del pago de la indemnización "más allá de las limitaciones cuantitativas establecidas en el contrato" carece de fuente jurídica que la justifique, y por tanto, no puede ser el objeto de una obligación civil”.

3."Las cláusulas limitativas de responsabilidad en materia de seguros -especialmente aquéllas que delimitan el riesgo asegurable- en tanto cláusulas de no seguro, no son ajenas a la víctima, esto es ella no puede ignorarlas, desde que su derecho a ser pagada por la compañía aseguradora del victimario se concretará en tanto la conducta de este último resulte involucrada en el riesgo que ha absorbido la entidad aseguradora. El seguro de responsabilidad civil se instituye en beneficio del asegurado, aunque en definitiva su efecto beneficioso pueda extenderse a terceros, pero ello será así en tanto el contrato lo permita”.

Aduce, asimismo, la minoría, que no media irrazonabilidad en la cuantía de la franquicia, porque la misma debe entenderse en relación directa con la prima a pagar y no con el quantum indemnizatorio que debe afrontar como límite el propio asegurado y, en definitiva, el damnificado.

En otras palabras, el sinalagma está conformado por el riesgo asumido por la aseguradora contra la prima pagada por el asegurado. Es en relación a ese vínculo que debe establecerse la razonabilidad o equivalencia de las prestaciones.

4. "Cuando se trata de un supuesto de limitación del riesgo o no seguro, no se debe omitir la aplicación de una cláusula de exclusión de la cobertura y resultan extrañas las consideraciones relativas a la función social del seguro y a la protección de la víctima”.

Afirma, por otro lado, la importancia de que los jueces no extiendan remedios coyunturales que puedan producir un descalabro en el sistema asegurador que, en definitiva, termine con el aseguramiento y ponga en peor posición aun a las víctimas de accidentes de tránsito. Termina afirmando que la decisión de la mayoría apareja un marcado apartamiento del fin rector de la seguridad jurídica, que ostenta jerarquía constitucional; cuya tutela incumbe justamente a los jueces, al fallar sin anclaje en la norma o, aun peor, prescindiendo de ella. 
A manera de adelanto, diremos que comulgamos con el criterio de esta minoría, y, en definitiva con los alcances de la interpretación que hace de estos supuestos la Corte Suprema de Justicia de la Nación -particularmente a través del voto del Dr. Ricardo Lorenzetti-, al establecer una clara distinción del contrato de seguro con franquicia y sus efectos, incorporando a la interpretación judicial las nociones del AED, relativas a la ponderación de las normas como incentivos para la evitación de conductas dañosas.

Asimismo, parece desprenderse del fallo, la consideración de la cláusula de franquicia como aquélla que delimita objetivamente el riesgo asegurado, con los fundamentos que ya expusiéramos.

\section{REPERCUSIONES DEL DECISORIO EN FALLOS POSTERIORES}

Ha dicho el Máximo Tribunal: "En el seguro de responsabilidad civil la franquicia pactada en la póliza es oponible al tercero damnificado... la Ley 17418 que específicamente establece que la sentencia de condena contra el responsable civil será ejecutable contra el asegurador "en la medida del seguro" (art. 118) 10 ".

Jueces inferiores también se han expresado en la misma línea. Sin perjuicio de los ya citados en epígrafes anteriores podemos traer a colación: "La franquicia así concertada resulta plenamente oponible al demandante (tercero damnificado) en tanto ese límite a la cobertura se enmarca en las condiciones particulares negociadas entre la asegurada y la citada en garantía, que en la especie están plasmadas en la póliza de modo que siendo el seguro un negocio contractual, la aseguradora sólo podrá ser asociada a la reparación del daño en los términos pactados, conforme lo prescripto en la norma precedentemente citada (art. 118, Ley 17418 y Resol. 25429/97 de la S.S.N.), la que no ha sido concretamente impugnada de constitucionalidad ${ }^{11}$ ".

Algunos fallos, además, han admitido su oponibilidad a los terceros, aún y más allá del supuesto contemplado en la norma que habilita su uso. Así, y en un caso referido a responsabilidad de las empresas concesionarias de peaje, se ha determinado la eficacia de la limitación opuesta por la aseguradora de la concesionaria a la actora damnificada, a través del fundamento de la inaplicabilidad al caso, de la doctrina "Obarrio y Gauna", -ergo, la doctrina de la inoponibilidad-, fundada en la impertinencia de la misma al caso sometido a resolución ${ }^{12}$. En

\footnotetext{
${ }^{10}$ CS, 2006/08/29, “Villareal, Daniel c. Fernández, Andrés y otros”. Revista RCyS. Año VIII, № X. Ed. La Ley, Buenos Aires. 2006, p. 73.

${ }^{11}$ CNCiv. Sala A, 2005/09/15, “Bossio, Jorge c. Expreso Paraná S.A. y otro. Revista RCyS. Año VIII, № VI. Ed. La Ley, Buenos Aires, Argentina. 2005, p. 58. CNCiv. Sala C, 2003/11/20 “Rodríguez Lucia c. Gamarra Wilfrido y otros. Revista RCyS. Año VI, No I. Ed. La Ley, Buenos Aires. 2004, p. 72; CNCiv., sala G, “Díaz, Dora c. Ayala Lombardo, Angel y otrso s. Daños y perjuicios”, 2011/11/22; CNCiv. Sala E, 2012/05/22, "Rollano Padilla Daniel c. El Puente S.A. de Transporte de Línea 32 y otros s. daños y perjuicios". Revista de RCyS. Año XIV. Número 8. Ed La Ley, Buenos Aires. Agosto de 2012, p.p. 236/240.

${ }^{12}$ CNCiv., sala D, “Aparicio, Ángel F. c/Grupo Concesionario del Oeste S.A. y otros”, 27/09/2010. RCyS. Año XIII, № 3, 2011. Págs. 230-231.
} 
otros, se ha hecho lugar a la oponibilidad sin hacer referencia alguna a este leading case ${ }^{13}$.

Por otra parte, un sector de la jurisprudencia se ha pronunciado en contra, no de la existencia de la franquicia y la validez de la cláusula entre las partes, sino en lo relativo a su oponibilidad al tercero damnificado ${ }^{14}$.

En igual sentido: "La cláusula en cuestión, se refiere a la relación interna entre el asegurado y su aseguradora; se trata de que ante un siniestro, el monto indemnizatorio se compartirá entre ellos, o que el asegurado asumirá hasta pesos cuarenta mil en relación a su aseguradora; pero en ningún momento la mentada cláusula se refiere a su aplicación frente a terceros, para habilitar a la aseguradora a exonerarse hasta tal limite ${ }^{15}$ ".

Se ha manifestado parte de la jurisprudencia en el sentido de establecer la nulidad parcial de la franquicia entre las propias partes del contrato (aseguradora - asegurado), arguyendo la desnaturalización del vínculo y la violación del art. 37, Ley 24240; para, a partir de allí, declarar la inoponibilidad de la misma, integrando el acuerdo ${ }^{16}$.

A partir de la reforma que sufriera la Ley 24240 (por Ley 26361) que derivó entre otras cosas en la ampliación del concepto legal de consumidor ${ }^{17}$, se incorporó al debate la idea del damnificado como consumidor del seguro, y a partir de allí, la postura de considerar la inaplicabilidad a las relaciones de consumo -de la que la víctima sería parte-, del concepto del efecto relativo de los contratos (arts. 1195, 1199 C. Civ.), que fuera utilizado como basamento normativo de uno de los argumentos a favor de la oponibilidad de la franquicia del fallo del Máximo Tribunal ${ }^{18}$.

"Según esta línea de pensamiento, a partir de la sanción de la Ley de Defensa del Consumidor $\mathrm{N}^{\mathrm{O}} 24240$, la introducción de un tercero -eventual víctima del siniestro- en el concepto del seguro de responsabilidad civil (insurance against liabilities to third parties) origina consecuencias relevantes, pues no cabe dudas que hoy está incluido en la relación asegurativa, aún

\footnotetext{
${ }^{13}$ En el caso de accidente ocurrido durante un recital en una cancha de futbol, se ha resuelto: "Si la demanda ha prosperado respecto de la aseguradora citada en garantía en los términos del art.118 de la ley 17.418 , debe entenderse que resultan plenamente oponibles a la víctima las condiciones de la franquicia establecidas en la póliza de seguro de responsabilidad civil, con lo cual no existe motivo alguno para diferir el tratamiento de la cuestión para la etapa de liquidación del crédito en tanto el alcance del deber de responder de la aseguradora se encuentra claramente delimitado”. C NCiv., sala E, “Orellana, Ángel Roberto c/ Dg Entertainment S.R.L.", 16/09/2009, en RCyS 2010-II, 177.

14 "La cláusula inserta en el contrato de seguro denominada franquicia o descubierto a cargo del asegurado no es oponible a la víctima porque para poder circular un vehículo automotor y sobre todo de las características del transporte público de pasajeros de gran porte y elevada masa que lo tornan más riesgoso o peligroso que un automóvil particular, se requiere contar con seguro que garantice a la eventual víctima la indemnización suficiente para cubrir sus daños y ello no puede ser dejado sin efecto por el contrato de seguro.,... por lo cual la aseguradora debe abonar la indemnización fijada en la sentencia, sin perjuicio de las acciones tendientes a requerir la colaboración que pactara con el asegurado CNCiv. sala B, 2004/10/08, “A., M. C. Lemo, Roberto E". Revista Responsabilidad Civil y Seguros. Año VII, № II. Ed. La Ley, Buenos Aires, Argentina. 2005. Pág. 68. En igual sentido, CNCiv. Sala B, 2003/10/24 “Terraza, Hugo c. Transportes Automotores Lujan S.A.C.I”. Revista Responsabilidad Civil y Seguros. Año VI, No I. Ed. La Ley, Buenos Aires, Argentina. 2004. Pág. 106.

${ }^{15}$ CN Civ. Sala C, 2006/03/21 “Kapp, Raquel c. Transportes Automotores Riachuelo S.A. y otro. Revista Responsabilidad Civil y Seguros. Año VIII, № VII. Ed. La Ley, Buenos Aires, Argentina. 2006. Pág. 75-76.

16 "Siendo inoponible al asegurado la franquicia que la compañía de seguros citada en garantía pactó con aquél, por desnaturalizar el vínculo contractual, corresponde integrar el contrato de manera que el asegurado participe en el siniestro
} 
cuando su efectiva incorporación se actualice con el acaecimiento del siniestro que lo damnifica" (PARRAL - SARTINI, 2011).

También se ha sostenido, con basamento en la Ley 24240 que: "las franquicias pactadas en el contrato de seguros de responsabilidad civil son nulas por abusivas, toda vez que su contenido y por el ejercicio que se hace de ellas se presentan circunstancias violatorias de los principios rectores como el orden público, la mortal y las buenas costumbres” ${ }^{19}$, toda vez que desnaturalizan las obligaciones, limitando la responsabilidad de la aseguradora, en los términos del art. 37, inc. $1^{\circ}$ de la Ley 24240.

En este punto, creemos que calificar la franquicia como una cláusula abusiva por ser limitadora de la responsabilidad de la aseguradora, choca de plano con el fundamento de verla como una forma de delimitación del riesgo económicamente eficiente y válida, de allí que disentimos con este criterio.

Por otra parte, resulta particularmente interesante mencionar el fallo dictado por la Corte Suprema de Justicia de la Nación ${ }^{20}$, al que posteriormente adhiere la Cámara Nacional Civil, sala $\mathrm{L}^{21}$, que rescata la inoponibilidad de las franquicias en los contratos de seguro de responsabilidad civil contratados por las empresas concesionaria del servicio de transporte ferroviario y subtes, al considerar que el monto tan elevado de la misma (en su caso U\$S 300.00o), desnaturaliza verdaderamente el contrato de seguro, y que por otra parte, no existe norma jurídica alguna que establezca el descubierto obligatorio como lo hace la Resol. 25429/97, SSN.

En materia de espectáculos públicos, ámbito que tampoco se ha visto regulado con la imposición de descubiertos obligatorios, también se ha expedido la jurisprudencia, aunque en el sentido de la oponibilidad de la franquicia contratada, respecto de la víctima de los daños ${ }^{22}$.

conforme las previsiones contenidas en el artículo 37 in fine de la ley de Defensa del Consumidor (Adla, LIII-D, 4125) -en el caso, el asegurado participa en un $10 \%$ de la indemnización que resulte de la sentencia judicial, incluyendo honorarios, costas e intereses a su cargo, en tanto no supere el $1 \%$ de la suma asegurada al momento del siniestro, por cada acontecimiento- aplicable al contrato de seguro por tratarse de un contrato de consumo". CNCom., sala A, "L., L. M. c/ Línea 146 Copla", 14/06/2007. RCyS 2007, 989.

\footnotetext{
${ }^{17}$ La importante reforma introduce la figura de bystander, el dañado colateral o adyacente a una relación de consumo. Ahora puede considerarse consumidor o usuario a quien de cualquier manera, esté expuesto a una relación de consumo

${ }^{18}$ CNCiv. sala M, “D’Amato, Jose Luis c. Microomnibus Norte SA s. Daños y perjuicios, 2009/ 04/06; CNCiv., sala L, “Pinedo, Domingo Sebastián c. Transporte Larrazábal Comercial e Industrial S.A., 2009/08/07; CNCiv., sala M, “Moran Marta Estela c. TBA Trenes de Buenos Aires SA., 2009/08/12. RCyS Año XII, Número 2, Febrero 2010.

${ }^{19}$ CNCiv., sala H, “García, Diego c. Velázquez Sosa y otros s. daños y perjuicios”, 2011/05/09.

20 "Barreiro, Jorge A. c. Transportes Metropolitanos Belgrano Sur S.A.", 2008/09/23.

21 "Zubiri, Luis c. Metrovías S.A. s daños y perjuicios” 2012/04/03.

22 "El alcance del deber de responder de la citada en garantía se encuentra claramente delimitado sin que se hayan arrimado planteos que demuestren que resulta válida su inserción en esta clase de contratos”. CNClv., sala E, “Orellana, Ángel c. Dg Entertainment S.R.L.", 2009/09/16. RCyS Año XII, Número 2, Febrero 2010
} 


\section{CONCLUSIONES}

Hemos pretendido a través de la sucinta recopilación de fallos respecto del tópico en análisis, mostrar la gran variedad de fundamentos a la hora de admitir o no la oponibilidad de la cláusula de franquicia al damnificado en los contratos de seguros de responsabilidad civil, adelantando en los respectivos acápites nuestra opinión al respecto.

Creemos conveniente concluir en la necesaria admisión del instituto de la franquicia en este tipo de seguros, siempre que la misma se apoye en un razonable límite a su cuantía o valor, y esté fundada en la buena fe, la equivalencia y el equilibrio económico en las prestaciones de las partes contratantes.

En esas condiciones, y en relación a la oponibilidad a terceros, la razonabilidad de la fijación del límite es el principio a tener en cuenta, y, a nuestro entender, el hilo vinculante entre las posturas de la doctrina judicial que aparecen a priori como antitéticas.

Y es que, analizando en profundidad las opiniones que surgen en el leading case "Obarrio" -en orden al llamado descubierto obligatorio impuesto por la Resolución de la Superintendencia de Seguros de la Nación-, la constitucionalidad o inconstitucionalidad de la franquicia, puede entenderse desde el modo en que se considere el monto fijado de $\$ 40.000$. Si se pretende como demasiado alto -y entonces no abarque la mayoría de los casus de responsabilidad civil, dejando fuera la cobertura, o desnaturalice la función de la aseguradora- será inoponible. Si se lo ve, en cambio, como un límite apropiado que posibilite y motive que el asegurado realice conductas diligentes para evitar tener que resarcir frente al daño causado, será considerada su oponibilidad.

Esta misma consideración se puede trasladar a aquellos casos en que no existe norma jurídica que imponga la franquicia, y donde los Jueces igualmente han ponderado el monto por sobre otras consideraciones acerca de la validez o eficacia del instituto como tal. Todo se reduce en definitiva al quantum.

Desde otra perspectiva, a partir de la incorporación del bystander los jueces habilitan la consideración del tercero damnificado como consumidor del seguro de responsabilidad civil, extendiendo la aplicación de las disposiciones de la Ley 24240 al universo de casos analizados (pensemos que en todos ellos los contratos de seguro se celebran entre empresas, con lo que no se podrían subsumir en la ley tuitiva), y la aplicación del art. 37 de la mencionada ley, que establece el carácter abusivo de las cláusulas que limiten la responsabilidad del predisponente, teniéndose las mismas por no escritas.

Si éste fuera el caso, hemos distinguido entre las cláusulas de limitación de responsabilidad de aquéllas que sólo limitan el riesgo asegurado como elemento esencial del contrato, y concluimos con la mayoría de la doctrina y jurisprudencia que la franquicia reviste la naturaleza de las segundas, consideradas válidas y eficaces, en tanto hayan sido aceptadas por las partes de buena fe.

Desde el punto de vista de considerar al damnificado como consumidor expuesto a las contingencias del contrato de seguro, incorporando a la aseguradora a la pléyade de sujetos responsables como proveedores de bienes y servicios (art. 40, Ley 24240), somos contestes a 
la opinión de algunos autores que postulan que esta solución sólo procura facilitar el resarcimiento de las víctimas, pero a largo plazo podría generar costos indeseados si se extiende indiscriminadamente a todos los aseguradores que tengan una relación contractual con proveedores de bienes y servicios (TOLOSA, 2010). En última instancia, afectaría el campo de la actividad de seguros, y paulatinamente aparejaría la muerte de la franquicia o la suba de su precio, desnaturalizando su finalidad.

Por último, entendemos que aún en el caso de considerar la nulidad de la cláusula por abusividad derivada del excesivo monto fijado para el descubierto, el mandato previsto en la propia disposición del art. 37, último párrafo para los jueces respecto de la integración del contrato, juntamente con la facultad de revisión que detentan los magistrados permitirían reestructurar o reequilibrar las cargas de la responsabilidad en cada caso concreto.

Pensamos que no basta con declarar inconstitucional una norma, o considerar solamente que una cláusula contractual nacida de un acuerdo de voluntades no debe tenerse por escrita, sino que existen "herramientas admitidas por la doctrina globalizada" (MOSSET ITURRASPE, 2008), que permiten al magistrado ajustar el contenido en base a la razonabilidad, propugnando soluciones más justas no sólo con el aquí y ahora, sino con las consecuencias de política económica que, innegablemente, las decisiones jurisprudenciales aparejan.

\section{REFERENCIAS BIBLIOGRÁFICAS}

Calabresi, G. (1970) The cost of accidents. A legal and economic analysis, Yale University Press.

Ciuro Caldani, M. A. (2011) Reflexiones sobre el riesgo, la responsabilidad y el aseguramiento. Revista de Responsabilidad Civil y Seguros. Año XIII. No 3 . Ed. La Ley, portada.

Font Ribas, A. (1999) Exclusión de cobertura y cláusulas limitativas. La delimitación del objeto y la limitación de derechos en el contrato de seguro. Revista de Derecho Privado y Comunitario. $\mathrm{N}^{\circ}$ 20. T.II. Ed. Rubinzal-Culzoni, Buenos Aires.

López Saavedra, D. M. (2007) Ley de Seguros -comentada y anotada-. Ed. La Ley, Buenos Aires.

Lorenzetti, R. L. (2010) Fundamento constitucional de la reparación de los daños. Revista de Responsabilidad Civil y Seguros. Año XII. Número 2. Febrero de 2010. Ed. La Ley, Buenos Aires. P.p. 265-279.

Meilij, G. (2012) Franquicia y descubierto obligatorio. Revista de Responsabilidad Civil y Seguros Año XIV, Número 7. Ed. La Ley, Buenos Aires. P.p. 207-210. 
Molina Sandoval, C. A. (2006) Seguro de responsabilidad civil y cláusulas "claims made". La cuestión de su validez en el Derecho Argentino. Working paper disponible en: http://www.msinfo.info/default/acienpol/bases/biblo/texto/boletin/2006/ BolACPS_2006_144_133-153.pdf

Mosset Iturraspe, J. - PIEDECASAS, M.A. (2008) La revisión del contrato. Ed. RubinzalCulzoni, Santa Fe.

Pagador Lopez, J. (1999) Condiciones Generales y cláusulas contractuales predispuestas. La ley de Condiciones Generales de la contratación. Ed. Marcial Pons, Barcelona.

Parral, P. - Sartini, M. (2011) El concepto de consumidor en el contrato de seguro: sentido y alcance de la reforma de la ley 26.361. Revista de Responsabilidad Civil y Seguros. Año XIII. Número 9. Ed. La Ley, Buenos Aires. P.p. 26-36.

Pérez -Serranoba González, J. L. (1993) El contrato de seguro. Interpretación de las condiciones generales. Ed. Comares, Granada.

Tamayo Jaramillo, J. (1999) "El seguro de responsabilidad civil por productos defectuosos” en Revista de Responsabilidad Civil y Seguros. Ed. La Ley. Buenos Aires.

Tolasa, P. (2010) El seguro obligatorio y la franquicia en un contexto de insolvencia: ¿Nuevas soluciones en la ley de defensa del consumidor?. Revista de Responsabilidad Civil y Seguros. Año XII. Número 2. Editorial La Ley, Buenos Aires. P.p. 139-167.

\section{CURRICULUM VITAE}

VERONICA MARIA LAURA GLIBOTA LANDRIEL

Abogada. Candidata a Doctora en Derecho por la Facultad de Derecho y Ciencias Sociales y Políticas de la UNNE (tesis doctoral en estado de aprobación).

Profesora adjunta regular de Instituciones de Derecho Privado II, docente regular de Instituciones de Derecho Privado I, de la Facultad de Ciencias Económicas de la UNNE.

Miembro del Instituto Nordeste de la Academia Nacional de Derecho de Córdoba.

Investigadora categorizada.

Miembro de equipo de investigación con proyecto acreditado.

vglibota@eco.unne.edu.ar 